\title{
Brain Superoxide Anion Generation during Asphyxia and Reventilation in Newborn Pigs
}

\author{
M. POURCYROUS, C. W. LEFFLER, R. MIRRO, AND D. W. BUSIJA \\ Departments of Pediatrics, Obstetrics/Gynecology, and Physiology and Biophysics, University of Tennessee, \\ Memphis, Memphis, Tennessee 38163
}

\begin{abstract}
Superoxide anion generation during severe asphyxia and reventilation was assessed in newborn pigs. Using closed cranial windows over the parietal cortices, superoxide dismutase (SOD)-inhibitable nitroblue tetrazolium (NBT) reduction was determined during asphyxia/ reventilation. Asphyxia was induced by turning off the respirator and occluding the endotracheal tube. In each animal, $2.4 \mathrm{mM}$ NBT dissolved in artificial cerebrospinal fluid was placed under one window and under the opposite window, NBT $(2.4 \mathrm{mM})$ plus SOD $(60 \mathrm{U} / \mathrm{mL})$ dissolved in artificial cerebrospinal fluid was used. A significant increase in SOD-inhibitable NBT reduction was observed in asphyxiated piglets $\left(14.67 \pm 4.5 \mathrm{pmol} / \mathrm{mm}^{2} \cdot 20 \mathrm{~min}\right)$ when compared with control piglets $\left(2.82 \pm 1.1 \mathrm{pmol} / \mathrm{mm}^{2} \cdot 20\right.$ $\mathrm{min})$. In another group in which the animals were treated with indomethacin $(5 \mathrm{mg} / \mathrm{kg}$ i.v.) before asphyxia/reventilation, there was minimal SOD-inhibitable NBT reduction. Our results indicate that superoxide anion is generated on the cerebral cortex during asphyxia/reventilation via the prostaglandin endoperoxide synthase pathway. (Pediatr Res 28: 618-621, 1990)
\end{abstract}

\section{Abbreviations}

NBT, nitroblue tetrazolium

SOD, superoxide dismutase

aCSF, artificial cerebrospinal fluid

CBF, cerebral blood flow

Perinatal asphyxia can occur in babies and may result in death, or damage to brain and other organs. Sequelae of brain damage are cerebral palsy, mental retardation, and epilepsy. The exact mechanisms that lead to brain damage are not known with certainty, but activated oxygen species, if produced, could be involved. Oxygen free radicals can damage or kill cells via several pathways, which include lipid peroxidation of membranes and inactivation of enzymes and transport proteins and DNA and RNA alterations $(1,2)$. Generation of oxygen free radicals in brain, such as superoxide anion, have been detected during exposure to arachidonic acid (3), acute hypertension (4), ische$\mathrm{mia} /$ reperfusion $(1,5,6)$, concussive brain injury $(7)$, extravascular blood (8), and seizures (9). Prostaglandin endoperoxide synthase metabolism of arachidonic acid appears to be the major source of free radicals produced by cortex in cats and piglets (3$5,8,9)$. Whether oxygen free radicals are produced in brain during asphyxia and reventilation is unclear. Rosenberg et al. (10) and Thiringer et al. (11) have provided suggestive evidence

Received March 5, 1990; accepted August 3, 1990

Correspondence: Massroor Pourcyrous, M.D., Newborn Center, 853 Jefferson Avenue, Room 201, Memphis, TN 38163.

Supported by grants from NIH and funds from the Department of Obstetrics and Gynecology. B.M. is supported by a Clinical Investigatorship from the NIH. using pharmacologic probes that oxygen free radicals are produced during asphyxia and reventilation in newborn lambs. However, brain production of oxygen free radicals was not measured.

The first purpose of our study was to test the hypothesis that superoxide anion radical is generated in the brain during asphyxia and reventilation in newborn pigs. The second purpose was to investigate the role of prostaglandin endoperoxide synthase in generation of superoxide anion. As an index of superoxide anion generation, we determined the amount of SODinhibitable NBT reduction on the cerebral surface.

\section{MATERIALS AND METHODS}

The animal protocols used were reviewed and approved by the Animal Care and Use Committee of the University of Tennessee, Memphis. Twenty-two newborn pigs (680 to $2000 \mathrm{~g})$ of either sex, $1-5 \mathrm{~d}$ of age, were anesthetized with ketamine-hydrochloride $(33 \mathrm{mg} / \mathrm{kg}$ intramuscularly) and acepromazine $(3.3 \mathrm{mg} / \mathrm{kg}$ intramuscularly). Anesthesia was maintained with $\alpha$-chloralose, 50 $\mathrm{mg} / \mathrm{kg}$ i.v. initially and then $10 \mathrm{mg} / \mathrm{kg}$ i.v. $/ \mathrm{h}$. A catheter was inserted into the femoral vein for injection of drugs and another catheter was inserted into the femoral artery to record blood pressure and to draw blood samples. The animals were ventilated with room air using a piston-type ventilator (Harvard Apparatus Co., Inc., S. Natick, MA). Temperature was maintained at 37$38^{\circ} \mathrm{C}$ by using a water-circulating heating pad. Closed cranial windows, as described previously $(5,8,9)$, were implanted over each parietal cortex. To implant the cranial window, the scalp was cut and reflected from the skull. A hole, approximately 2 $\mathrm{cm}$ in diameter, was made in the skull. An incision was made through the dura and arachnoid membranes and these membranes then were reflected over the edge of the bone. A stainless steel ring with a premounted glass coverslip was inserted in the hole. The window was cemented in place with dental acrylic. Three needles pierced the ring to allow injection of aCSF and NBT/SOD under the window and flushing of the brain surface with aCSF. The space under the window was filled with aCSF $\left(\mathrm{Na}^{+} 150 \mathrm{mmol} / \mathrm{L}, \mathrm{K}^{+} 3 \mathrm{mmol} / \mathrm{L}, \mathrm{Ca}^{2+} 1.25 \mathrm{mmol} / \mathrm{L}, \mathrm{Mg}^{2+} 0.6\right.$ $\mathrm{mmol} / \mathrm{L}, \mathrm{Cl}^{-} 132 \mathrm{mmol} / \mathrm{L}$, glucose $3.7 \mathrm{mM}$, urea $6 \mathrm{mM}, \mathrm{HCO}_{3}{ }^{-}$ $25 \mathrm{mmol} / \mathrm{L} ; \mathrm{pH} 7.33, \mathrm{PCO}_{2} 6.1 \mathrm{kPa}, \mathrm{PO}_{2} 5.7 \mathrm{kPa}$ ). The volume directly below the window was approximately $500 \mu \mathrm{L}$.

Experimental design. After placement of dual cranial windows in each animal, 20-30 min were allowed for stabilization. All animals received pavulon (pancuronium bromide) $0.1 \mathrm{mg} / \mathrm{kg}$ i.v. SOD-inhibitable NBT reduction was determined by placing NBT (Sigma Chemical Co., St. Louis, MO; $2.4 \mathrm{mM}$ ) dissolved in aCSF under one window and NBT $(2.4 \mathrm{mM}$ ) plus SOD (Sigma Chemical Co., $60 \mathrm{U} / \mathrm{mL}$ ) in aCSF under the other window. Then, 16 animals were randomized to control $(n=7)$ or asphyxia $(n=9)$ groups. The control animals were ventilated with room air for $20 \mathrm{~min}$. At that time, the brain surface was flushed with aCSF. Asphyxia was induced by turning off the ventilator and occluding the endotracheal tube for 5-7 min based on the 
animal's tolerance to asphyxia. Ventilation was resumed when the animal exhibited severe bradycardia (heart rate $<20 \mathrm{bpm}$ ) and/or blood pressure dropped to around $20 \mathrm{~mm} \mathrm{Hg}$. At the end of asphyxia, blood samples were taken for blood gas and $\mathrm{pH}$ analysis, and the animals reventilated with room air. At the end of $20 \mathrm{~min}$ (from the start of asphyxia through reventilation), the brain surface was flushed with aCSF. Therefore, the total amount of time the NBT/SOD solutions were under the windows was the same for all animals. Immediately after flushing the brain surface with aCSF, the animals were killed by i.v. injection of $\mathrm{KCl}$ and bled. A thin slice of the cortex under each cranial window was removed and frozen for later analysis. In a separate group ( $n=6), 30 \mathrm{~min}$ before asphyxia, piglets received indomethacin $(5 \mathrm{mg} / \mathrm{kg} / \mathrm{i} . \mathrm{v}$.) and the previously mentioned protocol (asphyxia plus reventilation) was repeated. We have shown previously that this dose of indomethacin reduces CSF levels of prostanoids under the window to nondetectable levels and blocks increases in CSF prostanoid levels to physiologic and pharmacologic stimuli $(12,13)$.

NBT is a yellow, water-soluble substance that in the presence of reducing agents converts to formazan, an insoluble, purple precipitate. Although NBT can be reduced by a variety of agents, SOD provides specificity for the assay. The SOD-inhibitable NBT reduction is determined by the differences in quantities of formazan precipitated on the brain surface under the two windows. The purple precipitate always is located under each cranial window and doesn't extend beyond the border of the window. Consequently, there doesn't appear to be significant intermixing between windows of fluids injected into the windows. Kontos (14) has shown minimal intermixing of NBT solutions between windows in the cat. By comparing the results from the two windows, we measured the NBT reduction caused by superoxide anion radicals because superoxide anion radicals are dismutated in the presence of SOD. Formazan was extracted from the brain slices into pyridine using the following method: The brain slices were minced, homogenized, and disrupted in a mixture of $0.1 \mathrm{~N}$ $\mathrm{NaOH}$ and $0.1 \%$ SDS in water. The volume was then increased to $3 \mathrm{~mL}$ with water, the mixture centrifuged at $20000 \times g$ for $20 \mathrm{~min}$, and the resultant pellet resuspended in $3 \mathrm{~mL}$ pyridine. The formazan was dissolved in the pyridine during heating at $80^{\circ} \mathrm{C}$ for $1 \mathrm{~h}$. A second centrifugation $(10000 \times g$ for $10 \mathrm{~min})$ removed any remaining particulate matter. The concentration of formazan in the resultant solution was determined (against a standard curve) spectrophotometrically at $515 \mathrm{~nm}$. Formazan for use in the standards was prepared freshly by reducing NBT dissolved in aCSF $(0.2 \mathrm{mg} / \mathrm{mL})$ with ascorbate $(1 \mathrm{mg} / \mathrm{mL})$. The standard was then handled identically and simultaneously with the samples and diluted in pyridine to produce concentrations from $100 \mathrm{ng} / \mathrm{mL}$ to $2 \mathrm{mg} / \mathrm{dL}$. The concentration of formazan against the light absorption is linear over this range. Values are presented as pmol NBT reduced $/ \mathrm{mm}^{2}$ in $20 \mathrm{~min}$.

Statistical analysis. Values for SOD-inhibitable NBT reduction and baseline values for arterial blood gases, $\mathrm{pH}$, and pressure were analyzed using an analysis of variance and the StudentNewman-Keuls test. For comparison of values from baseline and asphyxia conditions for blood gases, $\mathrm{pH}$, and arterial pressure, paired $t$ tests were used. A $p$ value $<0.05$ was considered significant. Values are represented as mean \pm SEM.

\section{RESULTS}

All three groups of animals had comparable arterial blood gases, $\mathrm{pH}$, and blood pressure at the start of experiment (Table 1). Duration of asphyxia was $6 \pm 0.4 \mathrm{~min}$ for the nonindomethacin-treated group and $7 \pm 1 \mathrm{~min}$ for the indomethacintreated group. Asphyxia decreased arterial blood pressure markedly and produced severe hypoxemia and acidosis (Table 1).

The SOD-inhibitable NBT reduction in the control group was minimal, whereas in the asphyxia/reventilated group, NBT reduction increased 4-fold (Fig. 1). In the indomethacin-pretreated group, SOD-inhibitable NBT reduction was no different than that in the control group (Fig. 1).

\section{DISCUSSION}

Our results indicate that superoxide anion radical is generated by the brain during asphyxia/reventilation in newborn pigs and that this generation can be eliminated by indomethacin pretreatment. In previous studies, we have determined superoxide anion production in piglets during ischemia/reperfusion (5), the presence of extravascular blood on the brain surface (8), and bicuculline-induced seizures (9). When comparing levels, we found that asphyxia/reventilation results in production of levels of superoxide anions comparable to that of ischemia/reperfusion and extravascular blood (Fig. 2).

The cerebrovascular consequences of free radical production by brain during asphyxia/reventilation are not fully understood. However, altered cerebrovascular responses have been described as a consequence of asphyxia/reventilation in lambs $(10,11)$. In addition, based upon our earlier studies using other interventions that produce superoxide anion, we expect the cerebral circulation to be compromised. For example, cerebral ischemia/reperfusion or chronic presence of blood on the cortex result in sufficient cerebrovascular damage to alter responses to specific stimuli such as arterial hypercapnia and hypotension and responses to acetylcholine and norepinephrine (15-19). A compromised cerebrovascular circulation would be at risk during additional episodes of asphyxia or any other insult or stress.

The specific events or conditions leading to superoxide anion production by brain are not known with certainty but can be suggested from knowledge of cardiovascular dynamics. We recently have characterized systemic and cerebrovascular responses to asphyxia and reventilation in piglets (20). By 1 min of asphyxia, CBF increased dramatically to all brain regions. However, by 5-6 min, blood flow to cerebrum, caudate nucleus, and cerebellum fell to below baseline values due to severe hypotension. With the onset of ventilation, arterial blood pressure increases dramatically to values higher than baseline, and $\mathrm{CBF}$ remains elevated for at least $16 \mathrm{~min}$. Based upon other studies, several stimuli for superoxide anion production are likely: 1)

Table 1. Arterial blood gas, $\mathrm{pH}$, and pressure values for piglets*

\begin{tabular}{|c|c|c|c|c|c|}
\hline & \multirow{2}{*}{$\begin{array}{c}\text { No asphyxia } \\
\text { (baseline) }\end{array}$} & \multicolumn{2}{|c|}{ No indomethacin group } & \multicolumn{2}{|c|}{ Indomethacin group } \\
\hline & & Baseline & Asphyxia & Baseline & Asphyxia \\
\hline $\begin{array}{l}\text { Arterial blood pressure } \\
(\mathrm{mm} \mathrm{Hg})\end{array}$ & $65 \pm 2$ & $57 \pm 3$ & $18 \pm 3 \ddagger$ & $61 \pm 4$ & $20 \pm 3 \neq$ \\
\hline Arterial blood $\mathrm{pH}$ & $7.41 \pm 0.06$ & $7.42 \pm 0.05$ & $7.15 \pm 0.04+$ & $7.48 \pm 0.06$ & $7.23 \pm 0.04 \ddagger$ \\
\hline $\mathrm{PCO}_{2}(\mathrm{kPa})$ & $4.2 \pm 0.1$ & $3.9 \pm 0.1 \dagger$ & $6.7 \pm 0.5 \ddagger$ & $4.5 \pm 0.1 \dagger$ & $7.6 \pm 0.7 \ddagger$ \\
\hline $\mathrm{PO}_{2}(\mathrm{kPa})$ & $10.4 \pm 0.7$ & $11.9 \pm 0.7$ & $1.6 \pm 0.1 \ddagger$ & $10.7 \pm 0.5$ & $1.9 \pm 0.4 \ddagger$ \\
\hline$n$ & 7 & 8 & 9 & 6 & 5 \\
\hline
\end{tabular}

$*$ Values are means \pm SEM.

$\dagger p<0.05$, compared to "no asphyxia" baseline value.

$\ddagger p<0.05$, compared to corresponding baseline. 


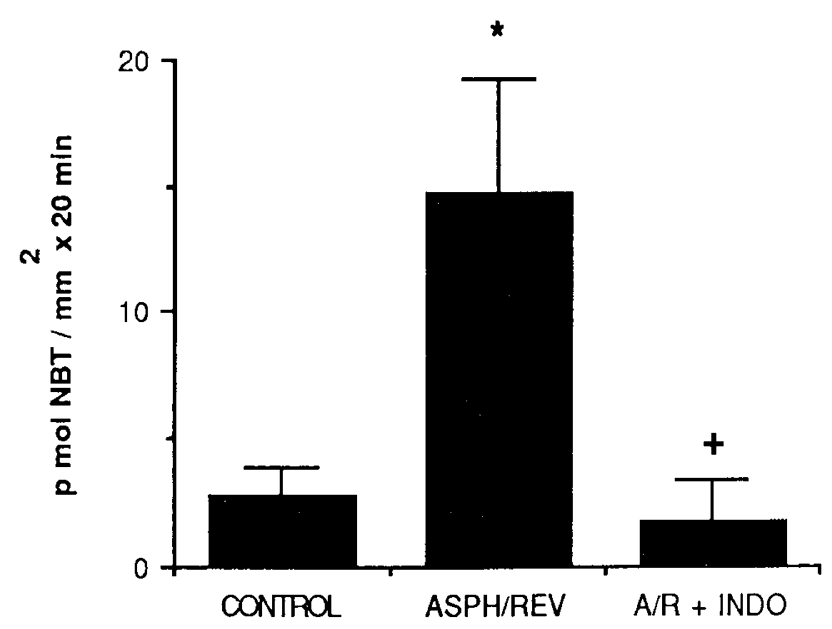

Fig. 1. Effects of no asphyxia (control; $n=7$ ), asphyxia and reventilation $(n=9)$, and indomethacin pretreatment plus asphyxia and reventilation $(n=6)$ on SOD-inhibitable NBT reduction in piglets. Values are mean \pm SEM. ${ }^{*}, p<0.05$ compared to control;,$+ p<0.05$ compared to asphyxia/reventilation.

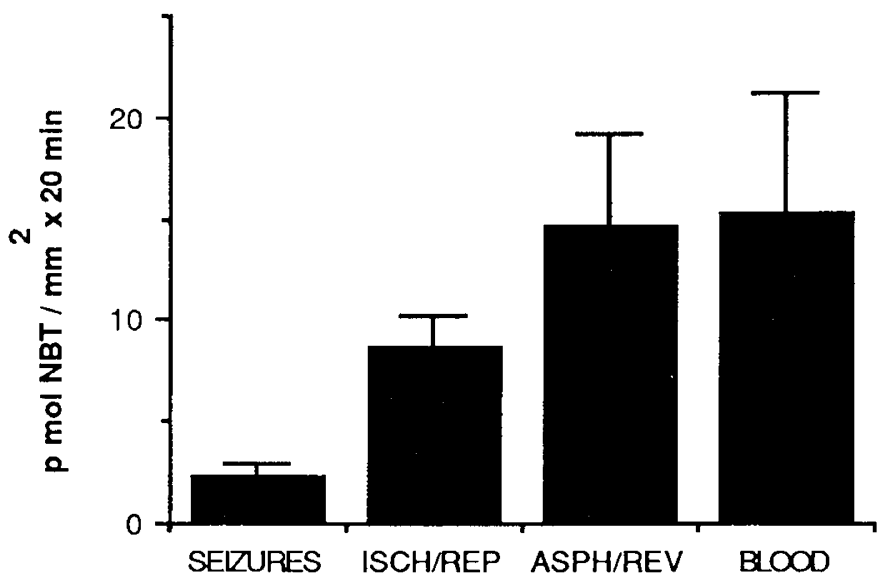

Fig. 2. Comparison of SOD-inhibitable NBT reduction in piglets during reperfusion after cerebral ischemia, asphyxia/reventilation, blood on the brain, and seizures. Although there is a tendency for SODinhibitable NBT reduction to be greater in the first three groups compared with the seizure group, the difference is not substantially significant using a one-way analysis of variance. Values are mean \pm SEM. Superoxide values are from previous publications for seizures (9), ischemia/reperfusion (5), and blood on the brain (8).

reintroduction of oxygen to ischemic brain; 2) the sudden rise in arterial pressure at the onset of reventilation (4); and 3) excessive release of excitatory amino acid transmitters (21). The increased levels of superoxide anions detected in our study are probably generated via the prostaglandin endoperoxide synthase pathway during reventilation and reintroduction of oxygen to the ischemic brain (22). Asphyxia, when prolonged, results in cerebral ischemia, which causes release of arachidonic acid (23) and modest production of prostanoids (24). Then, resuscitation with resultant reperfusion and reoxygenation would activate the prostaglandin endoperoxide synthase pathway further with production of prostanoids (24) and generation of oxygen free radicals. Our study doesn't rule out that substantial superoxide anion also could be produced during the asphyxia period, as has been suggested by Imaizumi et al. (25). However, based upon an earlier study (24), we believe that most of the superoxide anion is produced during reventilation. In piglets equipped with a closed cranial window, we found only a small increase in prostanoids during asphyxia, whereas much greater amounts were produced during reventilation (24). Consequently, if prostanoid production is linked to superoxide anion formation, most of the superoxide anion will be produced during reventilation. In other studies from our laboratories, we have shown that indomethacin pretreatment decreased the superoxide anion generation during ischemia/ reperfusion, blood on the brain, and bicuculline-induced seizures in newborn pig brain $(5,8,9)$. In our present study, the superoxide anion increase was virtually eliminated from cerebral cortex in asphyxia/reventilated piglets when they were pretreated with indomethacin.

The sudden rise in arterial pressure at the onset of ventilation could generate superoxide anion. Kontos and colleagues $(4,7)$ have shown that increases in arterial pressure by pharmacologic means or secondary to concussive head trauma leads to production of large amounts of superoxide radicals. Indomethacin limits this superoxide anion production during arterial hypertension and concussive brain injury $(4,7)$.

Our work extends and is complementary to that of three other laboratories. Thiringer et al. (11) found that treatment of asphyxiated newborn lambs with oxygen-free radical scavenger limited loss of somatosensory-evoked potentials and preserved increased postasphyxia CBF for a longer period of time. In addition, Rosenberg et al. (10) showed that administration of SOD and catalase prevented postasphyxia hypoperfusion in lambs. Further, Ment et al. (26) showed that i.v. administration of SOD protected puppy brain against intraventricular hemorrhage.

Indomethacin at the dose used does not appear to be an oxygen free radical scavenger, because it eliminates the radicals that are produced via the endoperoxide synthase pathway and not the radicals that are generated via the lipoxygenase pathway (22). Also, indomethacin inhibited generation of superoxide anion by activated platelets, but not by activated neutrophilic granulocytes (8), indicating further that only superoxide generated via endoperoxide synthase-dependent mechanisms is inhibited by indomethacin. In summary, during asphyxia/reventilation, superoxide anion is produced via the prostaglandin endoperoxide synthase pathway in the newborn pig.

Acknowledgments. The authors thank Alex Fedinec and John Pirani for excellent technical help. We thank Dr. W. Henckler and Merck, Sharpe and Dohme for the gift of indomethacin trihydrate.

\section{REFERENCES}

1. Cao UJ, Carney M, Duchan A, Floyd RA, Chevian M 1988 Oxygen free radical involvement in ischemia and reperfusion injury to brain. Neurosci Lett 88:233-238

2. Giratti A 1985 Mechanism of lipid peroxidation. J Free Radic Biol Med 1:8795

3. Kontos HA, Wei EP, Povlishock JT, Dietrich WD, Magrera CJ, Ellis EF 1980 Cerebral arteriolar damage by arachidonic acid and prostaglandin $\mathrm{G}_{2}$. Science 209:1242-1245

4. Kontos HA, Wei EP, Dietrich WD, Navari RM, Povlishock JT, Ghatak NR, Ellis EF, Patterson Jr JL 1981 Mechanism of cerebral arteriolar abnormalities after acute hypertension. Am J Physiol 240:H511-H527

5. Armstead WM, Mirro R, Busija DW, Leffler CW 1988 Postischemic generation of superoxide anion by newborn pig brain. Am J Physiol 255:H401-H403

6. Wei EP, Kontos HA 1987 Oxygen radical in cerebral ischemia. Physiologist 30:122(abstr)

7. Wei EP, Dietrich WD, Povlishock JT, Navari RM, Kontos HA 1989 Functional, morphological, and metabolic abnormalities of the cerebral microcirculation after concussive brain injury in cats. Circ Res 46:37-47

8. Mirro R, Armstead WM, Mirro J, Busija DW, Leffler CW 1989 Blood-induced superoxide anion generation on the cerebral cortex of newborn pigs. Am $J$ Physiol 257:H1560-H1564

9. Armstead WM, Mirro R, Leffler CW, Busija DW 1989 Cerebral superoxide anion generations during seizures in newborn pigs. J Cereb Biol Flow Metab 9:175-179

10. Rosenberg AA, Murdaugh E, White CW 1989 The role of oxygen free radicals in post-asphyxial cerebral hypoperfusion in newborn lambs. Pediatr Res 26:215-219

11. Thiringer K, Hrbek A, Karlsson K, Rosen KG, Kellmen J 1987 Post-asphyxial cerebral survival in newborn sheep after treatment with oxygen free radical scavengers and a calcium antagonist. Pediatr Res 22:62-66

12. Leffler CW, Busija DW 1985 Prostanoids in cortical subarachnoid cerebrospinal fluid and pial arterial diameter in newborn pigs. Circ Res 57:689-694 
13. Leffler CW, Busija DW 1985 Arachidonate metabolism on the cerebral surface of newborn pigs. Prostaglandins 30:811-817

14. Kontos H 1985 Oxygen radicals in cerebral vascular injury. Circ Res 57:508516

15. Busija DW, Leffler CW 1989 Cerebrovascular consequences of intracranial blood in piglets. Fed Proc 3:A1166(abstr)

16. Busija DW, Leffler CW 1990 Perivascular blood attenuates noradrenergic but not cholinergic effects on piglet pial arteriole. Stroke 21:441-446

17. Leffler CW, Busija DW, Armstead WM, Mirro R, Beasley DG 1983 Ischemia alters cerebral vascular responses to hypercapnia and acetylcholine in piglets. Pediatr Res 25:180-183

18. Leffler CW, Beasley DG, Busija DW 1984 Cerebral ischemia alters cerebral microvascular reactivity in newborn pigs. Am J Physiol 257:H266-H271

19. Leffler CW, Busija DW, Beasley DG, Armstead WM, Mirro R 1989 Postischemic cerebral responses to norepinephrine and hypotension in newborn pigs. Stroke 20:541-546

20. Pourcyrous M, Leffler CW, Busija DW 1990 Role of prostanoids in cerebro- vascular responses to asphyxia and reventilation in newborn pigs. Am J Physiol 259(in press)

21. Clark GD, Rathnear SM 1987 Blockade of excitatory amino acid receptors protects anoxic hippocampal slices. Neuroscience 21:665-671

22. Kukreja RC, Kontos HA, Hess ML, Ellis EF 1986 PGH synthase and lipooxygenase generate superoxide in the presence of NADM or NADPH. Circ Res 59:612-619

23. Yoshida S, Abe K, Busto R, Watson BD, Kogura K, Ginsbery MD 1982 Influence of transient ischemia on lipid-soluble antioxidants, free fatty acids, and energy metabolites in rat brain. Brain Res 245:307-316

24. Pourcyrous M, Leffler CW, Busija DW 1988 Post-asphyxial increases in prostaglandins in cerebrospinal fluid in piglets. Pediatr Res 24:229-232

25. Imaizumi S, Kayman T, Suzuki J 1984 Chemiluminescence in hypoxic brainThe first report correlation between energy metabolism and free radical reaction. Stroke 15:1061-1065

26. Ment LR, Stewart WB, Duncan CC 1985 Beagle puppy model of intraventricular hemorrhage: effect of superoxide dismutures on cerebral blood flow and prostaglandins. J Neurosurg 62:563-569

\section{Announcement}

\section{New Pregnancy Education Book Offered}

A new pregnancy educational booklet, Pregnancy Nutrition and You, has been introduced by Carnation Company to provide accurate, up-to-date information to mothers. Professionals who would like to receive a complimentary book as well as ordering instructions for additional copies of the book can submit their request on professional letterhead to: Carnation Company, P.O. Box 200, Pico Rivera, CA 90665. Additional copies require a nominal fee to cover shipping and handling. 